\title{
DISCUSSION
}

\section{Radial consolidation of a phase-change soil}

\author{
R. F. SCOTT (1990) Géotechnique 40, No. 2, 211-221
}

\section{G. Lefebvre, Université de Sherbrooke}

It is often by idealizing or simplifying complex phenomena that one can develop an understanding and appropriate analytical approaches to solve engineering problems. The consolidation of overconsolidated sensitive clays has proved difficult to evaluate by simple engineering approaches because of the rapid change in compressibility and permeability when the soil is loaded beyond the apparent preconsolidation pressure $\sigma_{\mathrm{p}}^{\prime}$. It is only by using more complex models requiring the use of computers that the phenomena can be satisfactorily simulated (Mesri and Choi, 1985). The Author has proposed an interesting, idealized and simplified model which considers the consolidation process as a phase-change process. At the simplest level, the model assumes that the clay under applied stress remains rigid up to the apparent preconsolidation pressure, at which it collapses to a new void ratio where it again remains rigid for higher pressures. The model has been tested for the one-dimensional compression of a sensitive clay foundation under a test embankment (Scott, 1989) and has allowed a good prediction of the evolution of the settlements with time. In this Paper, the Author applied the same model to the problem of radial consolidation of sensitive clay.

This discussion compares the assumptions of the idealized model with the actual behaviour and uses the Author's phase-change model to gain insight into a puzzling problem observed during triaxial compression of sensitive clay.

\section{Model assumptions and actual behaviour}

The assumption that, upon loading, the clay remains rigid with a void ratio of $e_{1}$ up to $\sigma_{\mathrm{p}}{ }^{\prime}$ does not introduce a significant error because structured clay is relatively incompressible, especially when considering the large compression which develops beyond $\sigma_{\mathrm{p}}^{\prime}$. The model assumes, however, that at $\sigma_{p}^{\prime}$ the clay suddenly collapses from $e_{1}$ to a new void ratio $e_{2}$. Studies of the microstructure of sensitive clays during consolidation have shown that the collapse of the clay structure takes place over a certain range of effective stress (Delage and Lefebvre, 1984). In other words, some intact (non-collapsed) large pores can still be observed under effective stress slightly beyond $\sigma_{\mathrm{p}}{ }^{\prime}$. Additional loading is necessary to generalize the collapse throughout the clay. This is evidenced by the results of oedometer tests where, at the end of primary consolidation, one can have a void ratio at mid distance between $e_{1}$ and $e_{2}$ for an effective stress slightly beyond $\sigma_{\mathrm{p}}{ }^{\prime}$.

For loading well beyond $\sigma_{\mathrm{p}}{ }^{\prime}$ and beyond the range of effective stresses in which the gradual collapse takes place, to assume an immediate total collapse at $\sigma_{p}^{\prime}$ would not introduce a significant error. It is only for loading ending slightly beyond $\sigma_{\mathrm{p}}{ }^{\prime}$ inside the range of effective stress in which the collapse is gradual that the Author's model could significantly overestimate the compression due to primary consolidation. It should be noted, however, that the overestimation of the compression would be attenuated by the large secondary compression associated with loading slightly beyond $\sigma_{\mathrm{p}}$.

At the end of the collapse, once the clay has reached the void ratio $e_{2}$, the clay is not rigid, but compressible like a normally consolidated clay. This can be accounted for by the Author's more complex model (Scott, 1989).

\section{Triaxial compression of sensitive clays}

Figure 9 shows the changes of volume $\varepsilon_{\mathrm{y}}$ and the axial compression $\varepsilon_{1}$ during the consolidation of a triaxial specimen of a sensitive clay. The general properties of clay are listed in Fig. 9. The radial compression $\varepsilon_{3}$ has been evaluated from the change of volume and the axial compression.

A specimen of Broadback clay in northern Québec, from a depth of $10 \cdot 4 \mathrm{~m}$, has been cut in a block sample retrieved using the Université de Sherbrooke sampler (Lefebvre and Poulin, 1979). The specimen was isotropically consolidated in a triaxial cell using $15-20 \mathrm{kPa}$ cell pressure increments applied at the end of primary consolidation. After consolidation under a cell pressure of $65 \mathrm{kPa}$, the clay did not yield in $\varepsilon_{1}$ or in $\varepsilon_{3}$. Under a cell pressure of $80 \mathrm{kPa}$, collapse is initiated in $\varepsilon_{3}$ and $\varepsilon_{\mathrm{v}}$ but not in $\varepsilon_{1}$. Under a pressure of $95 \mathrm{kPa}$, the curve of volume change $\varepsilon_{\mathrm{v}}$ or radial compression $\varepsilon_{3}$ would indicate that the collapse 


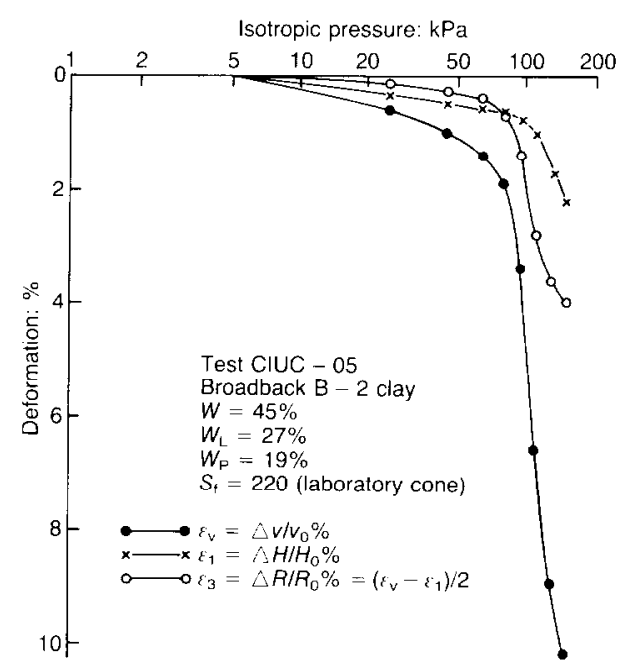

Fig. 9. Volumetric, axial and radial deformations during triaxial consolidation

of the clay structure is well under way. The axial compression $\varepsilon_{1}$, however, does not permit detection of any collapse. It is only under a cell pressure of $110 \mathrm{kPa}$ that the axial compression indicates an initiation of the collapse phenomenon.

The curves in Fig. 9 indicate that the specimen has collapsed or yielded in a radial direction at a pressure of $75 \mathrm{kPa}$, whereas in the vertical direction the clay structure has retained its rigidity until a pressure of about $105 \mathrm{kPa}$ has been reached. The problem is not that the clay has yielded first in the horizontal direction because it is known that in slightly overconsolidated clay the yield pressure in the horizontal direction is always lower than it is in the vertical direction. What is at first sight difficult to understand is how the soil structure could yield in the radial direction and at the same time retain its rigidity in the vertical direction.

The Author's phase-change model applied to radial consolidation brings some understanding to this puzzling phenomenon. The main feature of the phase-change model is a collapsing front advancing from the outer surface, at a rate controlled by the permeability of the collapsed clay.

Figure 10, using the same notation as Fig. 2, shows the phase-change at a time $t$ under a cell pressure beyond the horizontal yield stress but still below the vertical yield stress. Thus the collapse is initiated only at the perimeter of the clay specimen. At time $t$ the collapse front is located at a radius $R$ and defines an inner cylinder still rigid at a void ratio of $e_{1}$ and a collapsed outer zone where the void ratio has decreased to $e_{2}$. Collaps-

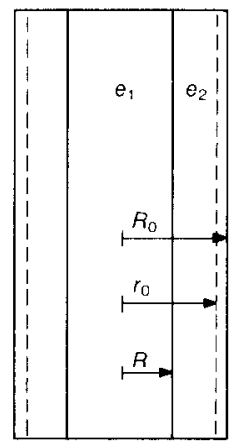

Fig. 10. Phase-change during triaxial consolidation

ing of the outer zone creates a large radial compression but no axial compression. In the Author's model, the clay in the outer collapsed zone is assumed as rigid. In the present case, it can be said that after collapse, the clay at a void ratio of $e_{2}$ is at equilibrium with the applied cell pressure, i.e. it can sustain the cell pressure without further primary compression.

Since the cell pressure is below the vertical yield stress of the clay, there is no collapse progressing from the top or bottom of the specimen. At time $t$ there is no axial deformation of the specimen hecause the central core of the specimen is still rigid and because the outer collapsed zone at a void ratio of $e_{2}$ is at equilibrium with the applied cell pressure. Thus, even at the end of primary consolidation, when the whole specimen will be at a void ratio of $e_{2}$, no axial deformation will be noted.

During triaxial compression of a phase-change soil with anisotropic yield stress, it appears that the collapse would result only in radial and not in axial deformation, giving the impression that the specimen has retained all its rigidity in the axial direction. In fact, the loss of rigidity could be identical in all directions after collapse.

The reasoning is straightforward if the cell pressure loading is such that it causes a complete collapse. If the collapse is not completed and if an increment of cell pressure is necessary to complete the collapse, the same reasoning can be applied assuming that the pores which have not collapsed in the previous loading have still an anisotropic yield stress. A small axial deformation should, however, be expected.

It has always been difficult to understand the non-simultaneous yield observed in the isotropic triaxial consolidation of sensitive clay as shown in Fig. 9. The observed behaviour appears, however, fairly logical when considered in relation to a phase-change model as proposed by the Author. 


\section{Author's reply}

The Author believes that what Professor Lefebvre has written is correct.

Inclusion of the results of oedometer tests on vertically and horizontally oriented samples of Broadback B-2 clay would have helped to define the values of $\sigma_{p}^{\prime}$ at which large compression develops.

The Author would like to suggest that the phase-change process may be associated with the initiation and development of the well-known flow slides in the sensitive clays of Canada and Scandinavia, because small external changes can elicit a significant response in clay. At a particular site such a clay may be in equilibrium, with the vertical effective stresses at the bottom of the layer just below the local value of $\sigma_{p}{ }^{\prime}$. Some relatively small disturbance, such as a surface loading, a lowering of the water table or a change in geometry, could result in the vertical stresses exceeding $\sigma_{\mathrm{p}}{ }^{\prime}$ at the base. In this circumstance, the lowest level of the clay will collapse, as it changes from the original void ratio $e_{1}$ to the new value $e_{2}$ and the pore water pressure will jump. The existing shear stresses in a sloping deposit of sensitive clay, adjacent to a river or excavation, may then exceed the shear strength of the material at the higher pore pressures, and movement be initiated. Indeed, an increase in the shear stress due, for example, to geometrical changes such as erosion may also lead to collapse of the most highly stressed base of the clay layer with an accompanying increase in pore pressure and diminution in strength.

\section{REFERENCES}

Delage, P. \& Lefebvre, G. (1984). Study of the structure of a sensitive Champlain clay and its evolution during consolidation. Can. Geotech. J. 21, No. 1, 21-35.

Lefebvre, G. \& Poulin, C. (1979). A new method of sampling in sensitive clay. Can. Geotech. J. 16, No. 1, $226-233$.

Mesri, G. \& Choi, Y. K. (1985). Settlement analysis of embankments on soft clays. J. Geotech. Engng Am. Soc. Civ. Engrs 111, No. 4, 441-464.

Scott, R. F. (1989). Consolidation of sensitive clay as a phase change process. J. Geotech. Engng Am. Soc. Civ. Engrs 115, Oct., No. 10, 1439-1458. 